\title{
The point-prevalence of alcohol use disorders and binge drinking in an Irish general hospital
}

\author{
Guy J Molyneux, Elizabeth Cryan, Elisa Dooley
}

Ir J Psych Med 2006; 23(1): 17-20

Abstract

Objectives: There is a paucity of data concerning the prevalence of alcohol use disorders and binge drinking in the general hospital adult population in Ireland. We therefore examined the point-prevalence of alcohol use disorders and of binge drinking in the adult inpatient population of the acute wards of an Irish university teaching hospital. The secondary aim was to examine gender, age, and patient group (medical/surgical) as risk factors.

Method: We administered the Alcohol Use Disorders Identification Test (AUDIT) to all consenting patients $(\mathrm{n}=$ 126) on the acute adult medical and surgical wards over one day.

Results: $76 \%$ of all inpatients on the acute medical and surgical wards were interviewed $(n=126)$ using the AUDIT.

Of the subjects $28 \%$ screened positive for an alcohol use disorder. Of these $91 \%$ were identified as binge drinkers.

A further $8 \%$ of the subjects screened positive for binge drinking but were not identified as having an alcohol use disorder.

Overall, $36 \%$ of the subjects screened positive for either an alcohol use disorder and/or for binge drinking using the AUDIT.

Male gender and under $65 \mathrm{~s}$ were risk factors for both alcohol use disorders and binge drinking.

Conclusions: The high point-prevalences of alcohol use disorders and binge drinking in hospital inpatients in particular are a cause for concern as they may have illness complicated by or secondary to undiagnosed alcohol excess. As this population is an easily accessible group for screening, and clinical and economic evidence supports intervention, we recommend screening all acute hospital admissions for alcohol use disorders and binge drinking, followed by appropriate management.

Key words: Alcohol; Alcohol dependence; Alcohol Use Disorders; Alcoholism; AUDIT; Binge drinking; Harmful

*Guy J Molyneux, MRCPsych, Department of Old Age Psychiatry, Liscarney House, Pearse Road, Sligo, Co Sligo, Ireland. Elizabeth Cryan, MD, MRCPsych, Department of Adult Psychiatry, James Connolly Memorial Hospital, Blanchardstown, Dublin 15, Ireland. Elisa Dooley, MB, Department of Adult Psychiatry, James Connolly Memorial Hospital, Blanchardstown, Dublin 15, Ireland.

${ }^{*}$ Correspondence

SUBMITTED: JUNE 9TH, 2005. ACCEPTED: JANUARY 18TH, 2006. drinking; Hazardous drinking; Hospital; Inpatients; Prevalence; Screening.

\section{Introduction}

The latest figures from the World Health Organisation (WHO) show that Ireland has the second highest per capita alcohol consumption (11.36 litres per capita) in the 25member $\mathrm{EU}^{1}$ and the fourth highest per capita consumption in adults in the world. ${ }^{2}$ These figures also show that this has more than doubled since 1970 (4.8 litres per capita) with most dramatic increases occurring since the mid-1990s (8.37 litres in 1994 to 11.36 litres in 2001).

Alcohol use disorders are defined by the WHO as being hazardous drinking, harmful drinking or alcohol dependence syndrome. Hazardous drinking is defined as a pattern of alcohol consumption that increases the risk of harmful consequences for the user or others. Harmful drinking is defined as alcohol consumption that results in consequences to physical and mental health. Alcohol dependence is defined as a cluster of behavioural, cognitive, and physiological phenomena that may develop after repeated alcohol use (Box 1). Binge drinking is defined separately to Alcohol Use Disorders by the $\mathrm{WHO}$, as drinking more than $60 \mathrm{~g}$ of absolute alcohol on one occasion ${ }^{3}$ by either sex (the equivalent in Ireland to six measures of spirits, six standard glasses of wine or three pints of beer ${ }^{4}$ ). We use the WHO definitions in this study.

High levels of alcohol use disorders in the community have been reported in Ireland ${ }^{5,6}$ and there is a widely reported emerging pattern of binge drinking. ${ }^{5}$ Irish drinkers have been shown to experience more adverse consequences of acute alcohol ingestion than drinkers in the other EU countries, ${ }^{5}$ and it is well known that both excess acute and chronic alcohol consumption are associated with adverse consequences including physical ${ }^{5,7}$ psychological $^{8}$ and social problems. ${ }^{5,9}$

There is also an economic cost to the state, and in 2003 the direct healthcare cost of alcohol disorders in Ireland was $€ 279 \mathrm{~m}$ with overall costs to the state of $€ 2.65 \mathrm{~b}$. $^{10}$

Therefore it is vital that we identify patients who have alcohol use disorders or binge drink, especially when they present to the general hospital services. Indeed the Royal College of Psychiatrists has recommended that all inpatients should be screened for alcohol problems. ${ }^{11,12}$

Although there is some data on the pattern of drinking and prevalence of alcohol disorders in the community ${ }^{2,5,6}$ we are aware of only one other study on the prevalence of alcohol disorders in the Irish general hospital population. ${ }^{13}$ That study indicated a high level (19\%) of DSM-IV defined alcohol 
dependence and abuse. We found no studies that examined the prevalence of binge drinking in hospital inpatients.

Therefore we studied the point-prevalence of alcohol disorders and included a specific focus on the point-prevalence of binge drinking in the acute inpatient population in James Connolly Memorial Hospital (JCMH). This is a suburban general teaching hospital with 174 acute medical, surgical, CCU and ICU beds serving a mainly Irish Caucasian suburban and rural population of 290,000 from a broad socio-economic background.

Our secondary aim was to examine gender, age, and patient group (medical/surgical) as risk factors for both alcohol use disorders and binge drinking.

\section{Methods}

Approval was obtained for the study from the hospital ethics committee.

All patients in the acute medical wards (including CCU) and surgical wards (including ICU) were included, and the Alcohol Use Disorder Identification Test ${ }^{3}$ (AUDIT) questionnaire was used as the study measure. This is a well-validated and reliable 10-item questionnaire ${ }^{14,15}$ developed by the $\mathrm{WHO}$ as a screening tool for alcohol use disorders. It has a maximum score of 40 , and a score of eight or more is positive. An Irish study ${ }^{13}$ in a similar population to ours found that the AUDIT was the most sensitive test (89\%) to identify alcohol abuse or dependence (DSM-IV defined) when a cut-off point of eight was selected. It also had a high specificity (91\%). The AUDIT has 10 questions examining hazardous drinking patterns, harmful drinking and symptoms of alcohol dependence over the previous twelve months. The AUDIT does not screen specifically for alcohol dependence syndrome although a score of 15 in males and 13 in females has been proposed as indicating alcohol dependence. ${ }^{16}$ Question three on the AUDIT examines the frequency of binge drinking and we used the score as an indication of its presence. The questionnaire is freely available from the WHO in self-report and interview versions. The raters were medical students who were on their psychiatry rotation, and were trained in the use of the AUDIT. They were selected to ensure that they were not involved with the clinical care of the patients. To reduce the social desirability bias the patient completed the AUDIT anonymously.

We applied the AUDIT to the entire acute ward population over one working day in January 2005, to obtain the pointprevalence. Written consent was obtained from each patient.

Where the subjects were able to, they completed the selfreport version. Otherwise the researchers used the interview version. The versions are identical.

We compared the gender and the type of patient ('medical' or 'surgical'), and categorised subjects into risk 'zones' as per $\mathrm{WHO}$ recommendations.

We used SPSS version 12.0.1 for Windows; Mann-Whitney $\mathrm{U}$ test for non-parametric data, and Chi-squared test and odds ratios for comparing binary/nominal data.

\section{Results}

Overall (Table 1)

Of the 166 patients registered on the ward census on the study day, $126(76 \%)$ completed the questionnaire. Of these 61 were male and 65 were female. Of the 40 who didn't

\section{Box 1: Definitions of terms used}

Hazardous drinking is a pattern of alcohol consumption that increases the risk of harmful consequences for the user or others. Hazardous drinking patterns are of public health significance despite the absence of any current disorder in the individual user.

Harmful use refers to alcohol consumption that results in consequences to physical and mental health. Some would also consider social consequences among the harms caused by alcohol.

Alcohol dependence is a cluster of behavioural, cognitive, and physiological phenomena that may develop after repeated alcohol use. Typically, these phenomena include a strong desire to consume alcohol, impaired control over its use, persistent drinking despite harmful consequences, a higher priority given to drinking than to other activities and obligations, increased alcohol tolerance, and a physical withdrawal reaction when alcohol use is discontinued.'

\section{Figure 1: Alcohol disorders and binge drinking prevalence in the} acute wards of a general hospital

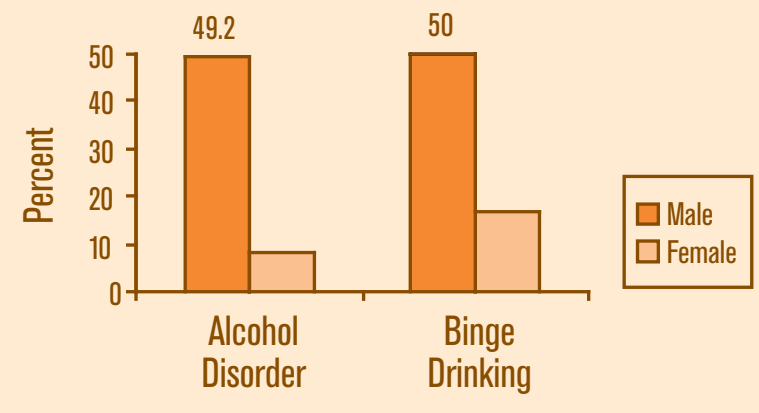

complete the questionnaire, 24 patients were unavailable due to illness severity or to being in theatre, 14 had been discharged before the researchers could assess them, and two questionnaires were incorrectly completed. No patients refused to complete the questionnaire.

Alcohol disorders (Table 2)

Of the patients $27.8 \%$ scored eight or more on the AUDIT, thus screening positive for an alcohol disorder (a point-prevalence in the inpatient population of 27,777 per 100,000).

Higher scores on the AUDIT indicate increased likelihood and severity of alcohol disorders and in our population $18.3 \%$ scored between eight and 15, and 9.5\% scored greater than 15.

A total of $25.4 \%$ scored zero, indicating abstinence for at least the past year.

\section{Binge drinking (Table 2)}

Of the patients who screened positive for an alcohol use disorder $91 \%$ were binge drinkers. In addition a further $8 \%$ of the subjects screened negative for alcohol use disorder but positive for binge drinking. Overall $33.3 \%$ of the subjects were binge drinkers (a point-prevalence in the inpatient population of 33,333 per 100,000$)$. Of these, $23 \%$ binge drank more than twice monthly, $18.3 \%$ binge drank more than twice weekly and $4 \%$ binge drank four or more times per week. Gender (Fig. 1, Table 2)

Men were much more likely to screen positive for alcohol disorders than women (49.2\% vs. $8.3 \%)$. Men scored higher on average than women (means $=8.7$ vs. $2.5, t$-test: $p<$ $0.01)$. 
Table 1: Age profile of subjects

$\begin{array}{lcllllll} & \text { Total completed AUDIT } & \text { Male } & \text { Female } & \text { Medical ward } & \text { Surgical ward } & \text { Age }<65 & \text { Age } \geq 65 \\ & (n=126) & (n=61) & (n=65) & (n=76) & (n=50) & (n=62) & (n=64) \\ \text { Mean age } & 60.2 & 57.3 & 62.9 & 64.1 & 54.2 & 41.4 & 78.4 \\ (\text { SD }) & (22.0) & (21.1) & (22.6) & (18.1) & (25.8) & (14.8) & (7.9) \\ \text { Range } & 16-102 & 16-90 & 16-102 & 16-90 & 16-102 & 16-64 & 65-102\end{array}$

Table 2: Results

\begin{tabular}{|c|c|c|c|c|c|}
\hline & $n(\%)$ & Mean age & $\begin{array}{l}\text { Male vs. female } \\
\text { odds ratio ( } 95 \% \text { CI) }\end{array}$ & $\begin{array}{l}\text { Under } 65 \text { vs. over } 65 \\
\text { odds ratio (95\%CI) }\end{array}$ & $\begin{array}{l}\text { Surgical vs. medical } \\
\text { odds ratio ( } 95 \% \mathrm{CI})\end{array}$ \\
\hline \multirow[t]{2}{*}{ Alcohol use disorders } & $35(27)$ & 48.5 & $49 \%$ vs $8 \%$ & $42 \%$ vs. $14 \%$ & $30 \%$ vs. $26 \%$ \\
\hline & & & $11.6(4.1-33.3)$ & $4.4(1.9-10.5)$ & $1.2(0.5-2.6)$ \\
\hline \multirow[t]{2}{*}{ Binge drinking } & $42(33)$ & 46.9 & $50 \%$ vs. $17 \%$ & $52 \%$ vs. $16 \%$ & $36 \%$ vs. $32 \%$ \\
\hline & & & $5.1(2.2-11.5)$ & $5.7(2.5-13.3)$ & $1.2(0.5-2.6)$ \\
\hline
\end{tabular}

Only $13.1 \%$ of males were abstinent over the past year, compared to $36.9 \%$ of females.

Men were more likely to binge drink than women $(50 \%$ vs. $17 \%)$.

Age (Table 2)

The under 65 population were more likely to score positive for alcohol disorders (41.9\%) than the over 65 s (14.1\%).

The under 65 population were more likely to binge drink $(52 \%)$ than the over 65 s (16\%).

Surgical versus medical patients

There were no significant differences between the medical and surgical wards in terms of screening positive on the AUDIT, mean scores or binge-drinking pattern.

\section{Discussion}

Our research indicates high point-prevalence of alcohol disorders and binge drinking in the general hospital acute ward population.

Of the study population $36 \%$ had either an alcohol use disorder and/or binge drank, with male gender and being under 65 as important risk factors (two thirds of the male under 65 population had an alcohol use disorder). Men were five times more likely to have an alcohol use disorder than women, and had a higher mean score on the questionnaire indicating greater risk for alcohol disorders of greater severity. Women were three times more likely to be abstinent than were men.

Binge pattern drinking was present in $33 \%$ of our study population, and $18.3 \%$ binge drink more than twice weekly. This reflects reports of a high prevalence of binge drinking in the Irish general population ${ }^{5}$ but is alarming given the association of binge drinking with adverse health, psychological and social consequences.

Increases in alcohol consumption and binge drinking in Ireland have been reported recently ${ }^{5}$, and although similar to population studies from the UK, ${ }^{17}$ they are in marked contrast to the Southern Europeans such as the French, who consume alcohol more frequently but drink less at each sitting and less overall. 2,5 Although binge drinking is commonly associated in the media with adolescent drinkers, the mean age of binge drinkers in our inpatient population was 46.9 indicating a significant prevalence in a relatively older population.

This study adds to the evidence that there are extremely high levels of alcohol use disorders and binge drinking in the hospital inpatient population. Evidence from other studies ${ }^{13}$ and our own experience as liaison psychiatrists suggest that the majority of these cases are not being diagnosed.

Clinical focus has tended to target alcohol dependence, often ignoring harmful drinking, hazardous drinking and binge drinking. This means that the opportunity to manage these problems, as well as the opportunity to decrease the risk of progression to alcohol dependence is missed. However the Strategic Task Force on Alcohol has recently recommended that a national screening protocol for early identification of problem alcohol use be established. ${ }^{4}$ Using questionnaires such as the AUDIT routinely in the general hospitals would allow us to screen for binge drinking, harmful use and hazardous use in addition to alcohol dependence. Its results may also direct clinicians to examine the patient for illnesses associated with alcohol use, and to advise patients whose alcohol consumption may interact with medications or other aspects of their treatment. Administering the questionnaire may also give an opportunity to educate patients about safe drinking habits.

It is important to note that unless particular attention is paid to the binge drinking question on the AUDIT questionnaire (question three), cases of binge drinking will be missed. In our study $8 \%$ of patients reported binge drinking but scored less than eight on the AUDIT overall (ie. they screened negative for WHO defined Alcohol Use Disorder).

Once identified the management of cases should then match the level of alcohol misuse, and the AUDIT has been developed with this in mind. ${ }^{18}$ Management should include referral for alcohol education and counselling, physical assessment, and detoxification treatment if necessary. Interventions such as brief education and counselling have been shown to be both clinically effective and cost-effective in reducing the level of drinking in persons with alcohol disorders $^{7,19}$ and brief intervention has been shown to be as 
effective as longer therapies in decreasing the amount of alcohol consumed. ${ }^{20}$ These interventions could be commenced whilst patients remain in hospital, or in the community after discharge. Clear pathways to care need to be developed for those identified. The screening and management of alcohol use disorders and binge drinking in general hospitals will have service planning implications. Staff will need to be trained and resourced to administer the screening tool. The question of who will administer the tool needs to be answered but according to the $\mathrm{WHO}$ and in our experience, any health worker with a minimum of training can administer the AUDIT.

The Faculty of Substance Misuse Of the Irish College of Psychiatrists have recommended the development of specialist multidisciplinary outpatient addiction teams. ${ }^{21}$ These teams could offer integrated community follow-up to patients identified in the general hospital. However there may still be a need for appropriately trained counsellors to give education and brief counselling in the general hospital, as some patients may choose not to attend community follow-up clinics.

There will certainly be a need to foster close links between the hospital-based clinicians and the community alcohol services.

\section{Conclusion}

The volume of alcohol being drunk per capita in Ireland has increased dramatically over the last 30 years ${ }^{2}$ and evidence suggests this is having a serious effect on the nations health ${ }^{6}$ with major economic consequences. ${ }^{10}$ This study demonstrates that there are high levels of alcohol disorders and binge drinking in the general hospital acute population. Therefore we believe there is an urgent need for screening for, and management of, alcohol use disorders and binge drinking in general hospitals. The study also suggests that the AUDIT questionnaire is quick to complete, and is acceptable in this population.

The inpatient population is one that easily facilitates screening and may benefit greatly from screening for alcohol disorders. However it is also one that is currently and regretfully often neglected in this regard. We suggest that all patients admitted to general adult hospitals be screened for alcohol disorders, followed by appropriate management.

The strengths of this study are: 1) We used a well validated and reliable study measure; 2) Despite the current level of interest there is little research previously on binge drinking in this population; 3 ) The data collection was anonymous which helps to minimise social desirability bias; 4) The study has direct service implications

Weaknesses of this study are: 1) We did not confirm the diagnosis using a semi-structured interview (however the AUDIT has been validated previously in this manner); 2) The subjects who completed the interview version of the AUDIT may have tended to minimise their drinking, thus underestimating the level of alcohol use disorders; 3 ) Although the AUDIT is concerned with drinking habits during the previous 12 months, the fact that the questionnaire was administered in January may have led to higher scores due to the recency of the December holiday period.

Further recommendations include: a larger study should be conducted to facilitate further identification of high risk groups; an intervention study with follow-up should be conducted to ascertain if screening and intervention is effective in this population.

\section{Acknowledgements}

Thank you to the undergraduate psychiatric students of the Royal College of Surgeons in Ireland for their assistance in collecting the data for this study.

\section{Declaration of Interest: None}

References

1. WHO. Health For All database, 2001

2. FAO (Food and Agriculture Organisation of the United Nations). World Drink Trends

2003.
3 . The Alcohol Use Disorders Identification Test. Second edition. World Health Organisation.

4. Strategic Task Force on Alcohol, Second Report. September 2004. Dublin, Ireland: Health Promotion Unit, Department of Health and Children, 2004

5. Ramstedt M, Hope A. The Irish drinking habits of 2002: Drinking and drinking related harm, a European comparative perspective. Journal of Substance Use. In press.

6. Health Promotion Unit, Department of Health and Children and the Centre for Health Promotion Studies, National University of Ireland, Galway. Survey of lifestyle attitudes and nutrition (SLÁN). In: The National Health and Lifestyle Surveys. Dublin, Ireland: Health Promotion Unit, Department of Health and Children, 2003.

7. Babor T et al. Alcohol: no ordinary commodity - research and public policy. World Health Organisation and Oxford University Press, 2003.

8. Gilman SE. A longitudinal study of the order of onset of alcohol dependence and major depression. Drug Alcohol Depend 2001; 63(3): 277-86.

9. National Crime Council. Public Order Offences in Ireland. A report by the Institute of Criminology, Faculty of Law, University College Dublin for the National Crime Council, 2003.

10. Byrne S. Updates on the estimates on the cost of alcohol problems in Ireland. Dublin, Ireland: Central Statistics Office Annual Reports, 2004.

11. Marshall J. Annual meeting of the Royal College of Psychiatrists in 2004 12. Royal College of Psychiatrists. The Psychological Care of Medical Patients: Recognition of Need and Service Provision. London: Tavistock, 1995.

13. Hearne $\mathrm{R}$ et al. Alcohol Abuse: prevalence and detection in a general hospital. J Royal Soc Med, 2002; 95:84-87.

14. Bohn MJ, Babor TF, Kranzler HR. The Alcohol Use Disorders Identification Test 14. Bohn MJ, Babor TF, Kranzler HR. The Alcohol Use Disorders Identification Test
(AUDIT): validation of a screening instrument for use in medical settings. Journal of (AUDIT): validation of a screening instr

15. Piccinelli M, Tessari E, Bortolomasi M, Piasere O, Semenzin M, Garzotto N, Tansella 15. Piccinelli M, Tessari E, Bortolomasi M, Piasere O, Semenzin M, Garzotto N, Tansella
M. Efficacy of the Alcohol Use Disorders Identification Test as a screening tool for M. Efficacy of the Alcohol Use Disorders Identification Test as a screening tool for
hazardous alcohol intake and related disorders in primary care: a validity study. BMJ hazardous alcohol int

1997; 314: 420-24.
16. Bergman H, Källmen H. Swedish women have developed more risky and more 16. Bergman $\mathrm{H}$, Källmen $\mathrm{H}$. Swedish women have developed more risky and more
harmful alcohol drinking habits. A survey of alcohol drinking changes among Swedes between 1997 and 2001. Läkartidningen 2003; 100: 1028-30.

17. Jefferis BJMH, Power C, Manor O. Adolescent drinking level and adult binge drinking in a national birth cohort. Addiction 2005; 100(4): 543-50.

18. Babor T, Higgins-Biddle JC. Alcohol screening and brief intervention: dissemination strategies for medical practice and public health. Addiction 2000; 85(5): 677-86. 19. Fleming MF, Mundt MO, French MT, Manwell LB, Stauffacher EA, Barry KL. Brief physician advice for problem drinkers: long-term efficacy and benefit-cost analysis. Alcoholism: Clinical and Experimental Research 2002; 26: 36-43.

20. Moyer A, Finney JW, Swearingen CE, Vergun P. Brief interventions for alcohol problems: a meta-analytic review of controlled investigations in treatment seeking and non-treatment seeking populations. Addiction 2002; 97(3): 279-93.

21. Developing and delivering world-class alcohol treatment services in Ireland. A response to the 'Strategic Taskforce on Alcohol, Second Report'. Submission from the Faculty of Substance Misuse Of the Irish College of Psychiatrists; March 2005. 